\title{
Neuritic leprosy: epidemiology and therapeutic responsiveness
}

\author{
S TALWAR, P K JHA \& V D TIWARI \\ Skin Centre, Base Hospital, Lucknow 226002, India
}

Accepted for publication 24 April 1992

\begin{abstract}
Summary We studied epidemiology, progression and therapeutic responsiveness in 62 cases of neuritic leprosy. Numbness was the main presenting symptom. Mononeuritis involving the ulnar nerve, followed by the common peroneal nerve was the commonest presentation. The lepromin test was positive in 34 cases while a slit-skin smear was negative in all cases. We treated 20 of these cases with dapsone monotherapy and 5 cases $(25 \%)$ developed a skin lesion after an average duration of 3 months' treatment. We treated 42 cases with a combination of dapsone and rifampicin, and 3 cases $(7 \%)$ developed a skin lesion after an average duration of 2-6 months. The subsequent diagnosis in cases developing skin lesions was borderline-lepromatous in 1 case, borderline-tuberculoid in 4 cases, tuberculoid in 2 cases and indeterminate in 1 case.
\end{abstract}

\section{Introduction}

Leprosy is regarded as the commonest cause of severe neuropathy in developing countries. ${ }^{1}$ However, neuritic leprosy has always been a controversial subject. Wade ${ }^{2}$ introduced a subgroup of polyneuritis in the classification of leprosy and this was accepted at the Madrid conference ${ }^{3}$ and also included in the Indian leprologists' classification. ${ }^{4}$ Cochrane ${ }^{5}$ et al. and Noordeen ${ }^{6}$ preferred the term neuritic to polyneuritic because many cases present with a mononeuritis. Further confusion arose with the use of the term primary neuritic for cases where nerve involvement was seen without a skin lesion and secondary neuritis for the cases where nerve trunk involvement was secondary to development of a skin lesion. Hansen and Looft $^{7}$ considered nerve involvement as secondary to the development of skin lesions while Desikan et al. ${ }^{8}$ considered leprosy to be neutral in inception. However, such a distinction is no longer maintained and the term neuritic leprosy is used as synonymous with pure/ primary neuritic leprosy. The neuritic group has further been subdivided into tuberculoid, dimorphous and lepromatous subgroups on the basis of the histological findings. ${ }^{9}$

We have tried to evaluate the status of neuritic leprosy by studying the epidemiology, progression and therapeutic responsiveness. 


\section{Materials and methods}

In a retrospective study we analysed data of 42 cases of neuritic leprosy amongst male army personnel who had been treated with multidrug therapy-dapsone $100 \mathrm{mg}$ per day and rifampicin $600 \mathrm{mg}$ per month-between 1983 and 1990. For comparison 20 cases of neuritic leprosy treated before 1983 with dapsone monotherapy (100 mg per day) were also included.

Neuritic leprosy was diagnosed if there was anaesthetic skin area, weakness/wasting of muscles, or tingling sensation/neuralgic pain accompanied by nerve trunk thickening. Routinely, a skin biopsy was done before treatment from a maximal anaesthetic area and if histopathological evidence of leprosy was found the case was excluded from the study. Slit-skin smears (SSS) were performed from both ears, buttocks and an anaesthetic area in all cases. A lepromin test (Dharmendra antigen) was also carried out. However, a nerve biopsy was not performed in any of the cases. All these cases were offered institutional antileprosy treatment for 6-12 months. Following treatment patients were observed for 1 to 5 years. A skin biopsy was performed in those cases that developed skin lesions during institutional therapy or thereafter, and these were subsequently classified by the RidleyJopling method.

\section{Results}

ON MULTIDRUG THERAPY (42 CASES)

A total of 392 paucibacillary cases of leprosy were given institutional treatment at our centre between 1983 and 1990. (Our centre offers institutional treatment to paucibacillary cases only.) These cases were classified as indeterminate-113, tuberculoid-99, borderline-tuberculoid-138, neuritic - 42 , and the proportion of neuritic cases was $10 \cdot 7 \%$. The details of complaints at onset in 42 neuritic cases are given in Table 1 and the commonest is numbness. The average delay before seeking medical advice was 3 months after detection by the patient and the average age was 32 years. None of these patients had any family history of leprosy and no regional predeliction was noted. The details of nerve involvement are given in Table 2 (a). SSS for AFB was negative in all cases. The lepromin test was positive in 26 cases and negative in 16. All 42 cases were put on multidrug therapy, and 3 developed skin lesions af ter an average period of 2.6 months following therapy. The

Table 1. Presenting symptoms in cases of neuritic leprosy treated with multidrug therapy

\begin{tabular}{lc}
\hline Initial complaint & $\begin{array}{c}\text { No. of } \\
\text { cases }\end{array}$ \\
\hline Numbness & 27 \\
Weakness & 22 \\
Wasting & 7 \\
Deformity & 7 \\
Tingling/Pain & 5 \\
\hline
\end{tabular}


Table 2. Details of nerve involvement in cases treated with (a) multidrug therapy, and (b) dapsone monotherapy

\begin{tabular}{lcc}
\hline Nerves involved & $\begin{array}{c}\text { (a) No. of cases } \\
\text { treated with MDT }\end{array}$ & $\begin{array}{c}\text { (b) No. of cases } \\
\text { treated with dapsone monotherapy }\end{array}$ \\
\hline Ulnar & 17 & 9 \\
Radial & 2 & 2 \\
Lateral popliteal & 8 & 6 \\
Medial cutaneous nerves of forearm & 2 & $\frac{3}{3}$ \\
Multiple nerves & 13 & \\
\hline
\end{tabular}

subsequent diagnosis in these 3 cases was 2 cases of borderline-tuberculoid and 1 case of tuberculoid.

\section{ON DAPSONE MONOTHERAPY (20 CASES)}

The majority (16) of these cases presented with numbness as the initial complaint. Weakness of hands/feet was noted in 13 cases, muscle wasting in 12 and deformity in 3 . The details of nerve involvement are given in Table 2(b). SSS for AFB was negative in all cases. The lepromin test was negative in 8 cases and positive in 12. During surveillance af ter starting treatment 5 of these 20 cases developed skin lesions which were clinically and histopathologically suggestive of leprosy; the average interval between initiation of therapy and development of skin lesion was 3 months. The subsequent diagnosis in these 5 cases was 1 case of borderline-lepromatous, 2 of borderline-tuberculoid, 1 of tuberculoid, and 1 of indeterminate.

\section{Discussion}

Neuritic leprosy, which has been reported in India to be between $5 \cdot 5 \%{ }^{10}$ and $17 \cdot 7 \%{ }^{6}$ of all leprosy cases, accounted for $10.7 \%$ of all paucibacillary cases in the present series. This high incidence justifies its inclusion under a separate independent subgroup in the Indian classification. Although Ridley-Jopling did not include neuritic leprosy as a separate subgroup in their classification they clearly stated that neural leprosy can occur in any kind of spectrum leprosy apart from LL. ${ }^{11}$ Mononeuritis is the commonest presentation, and was seen in $74 \%$ of the patients. This was also observed by Noordeen ${ }^{6}$ and Uplekar $\&$ Antia $^{12}$ and lends support to the shift of terminology from polyneuritis to neuritis. Like Uplekar \& Antia $^{12}$ we also found the ulnar nerve to be the commonest involved nerve, followed by the lateral popliteal, while Noordeen ${ }^{6}$ observed the lateral popliteal to be commonly involved. Median nerve thickness as mononeuritis was not observed by us while in polyneuritic leprosy it was observed in 3 cases. Radial nerve thickness was generally noted at the wrist, and $25 \%$ of our patients on dapsone monotherapy developed skin lesions. This relatively high incidence observed, compared with other reports, may be because in the army the strict periodic medical examination of soldiers facilitates early case detection. Many of these cases would have reported with skin lesions at onset had their disease not been detected at an earlier stage. A case of polyneuritic leprosy who 
developed multiple skin lesions after 3 months of monotherapy was diagnosed as borderline-lepromatous leprosy. SSS which were negative earlier subsequently became positive. However, he subsequently showed a good response to therapy. The lepromin test remained negative throughout. Waters et al. ${ }^{13}$ reported a case with radial nerve thickness, histologically diagnosed on nerve biopsy as borderline-lepromatous leprosy. However, they feel that the skin lesion in this case was missed because of hysterical anaesthesia.

Experimental evidence has suggested the $\operatorname{skin}^{14}$ as well as the upper respiratory $\operatorname{tract}^{15}$ to be the routes of entry for $M$. leprae. We feel that entry through the skin produces the mononeuritic type of disease while the respiratory route may be responsible for the polyneuritic type of disease. It has been postulated that after entering through the skin $M$. leprae invades axonoplasmic filaments and only af ter rupture of the Schwann sheath can the organism burst into the corium of the skin. ${ }^{3}$ Therefore the bacillary load in nerves is found to be higher than that observed in the associated skin lesion. However only 3 patients out of $42(7 \%)$ on multidrug therapy subsequently developed skin lesions. This suggests that prompt and better killing of the organism by MDT arrests the spread of the disease from the nerves to the skin. This also supports the suggestion of Desikan ${ }^{8}$ that leprosy is neural in inception. Other workers ${ }^{6,16}$ have also reported the development of skin lesions in neuritic leprosy when treatment is irregular. This indicates the efficacy of the early introduction of therapy in neuritic leprosy for the prevention of the development of skin lesions, this being more beneficial with MDT compared to monotherapy. The possibility of developing new skin lesions while on treatment as part of a reversal reaction has been mentioned earlier. ${ }^{17}$ Can appearance of skin lesions in neuritic leprosy be a part of reversal reaction and monotherapy/multidrug therapy have a role in modifying its incidence? The importance of a biopsy from normal looking anaesthetic skin is to exclude a cutaneous leprosy lesion which may not be clinically apparent but histopathological evidence may be convincing, as has been reported earlier. ${ }^{10,18,19}$ The possibility of different strains of $M$. leprae to explain the various combinations of skin and nerve involvement has already been ruled out by Rees. ${ }^{20}$

Noordeen ${ }^{6}$ observed that there is a tendency for spontaneous regression of a thickened nerve even without treatment. However, we observed that cases with a relatively longer duration of illness reported with weakness and deformity. In general, it is our observation that nerve thickness takes longer to regress compared to the associated skin lesion, also confirmed by Srinivasan et al. ${ }^{21}$ in histological studies.

Meralagia paraesthetica is the important clinical differential diagnosis in neuritic leprosy. These cases do not improve on antileprosy treatment and local infiltration of lignocaine and steroids medial to the anterior superior iliac spine has been reported to improve this condition in some patients.

Sometimes compression of the lateral popliteal nerve due to prolonged working in a squatting posture leads to weakness/anaesthesia of the foot. However, this is transitory and should be carefully excluded.

\section{References}

1 WHO Peripheral neuropathies. Technical Report series No 654, 1980.

${ }^{2}$ Wade HW. The classification of leprosy. A proposed synthesis based primarily on the Riode Janeiro-Havana System. Int J Lepr, 1952; 20: 429-462.

3 International Congress on Leprosy, Madrid. Report of the committee on classification. Int J Le pr, 1953; 21: 504. 
${ }^{4}$ All India Leprosy Workers Conference. Classification of leprosy adopted by the Indian association of leprologist. Lepr India, 1955; 27: 93.

${ }^{5}$ Cochrane RG, Smyly HH. Leprosy in theory and practise, Cochrane RG, Davey TF (ed). Bristol: John Wright and Sons, 1964; p. 203.

6 Noordeen SK. Epidemiology of (Poly) neuritic type of leprosy. Lepr India, 1972; 44: 91-96.

7 Hansen GA, Looft C. Leprosy in its clinical and pathological aspect. Translated by M Walker. Bristol: John Wright and Company, 1895; p. 67.

${ }^{8}$ Desikan KV, Ramu G, Girdhar BK, Naryanan RB. Histopathological analysis of pure neuritic leprosy, Proceedings of XII International Leprosy Congress, New Delhi, 20-25 February 1984. Print aid New Delhi, pp. 439-441.

9 Cochrane RG, Khanolkar VR. Dimorphous polyneuritic leprosy. Ind J Med Sci, 1958; 12: 1-9.

10 Dongre VV, Ganapati R, Chulawala RG. A study of mononeuritic lesions in a leprosy clinic. Lepr India, 1976; 48: 132-137.

11 Ridley DS, Jopling WH. Classification of leprosy according to immunity-A five group system. Int J Lepr, 1966; 34: 255-273.

12 Uplekar MW, Antia NH. Clinical and histopathological observations on pure neuritic leprosy. Ind J Lepr, 1986; 58: 513-521.

13 Waters MFR, Ridely DS, Ridely MJ. Clinical problems in the initiation and assessment of multidrug therapy. Lepr Rev, 1986; 57, supplement 3: 92-100.

14 Job CK, Sanchez RM, McCormick GT, Hastings RC. First lesion in experimental armadillo leprosy. Int $J$ Lepr, 1985; 57: 71-77.

15 Barton RPE. A clinical study of the nose in lepromatous leprosy. Lepr Rev, 1974; 45: 135-144.

16 Shenoi SD, Padhee A. Polyneuritic leprosy changing into borderline tuberculoid (BT). Ind J le pr, 1990; 62: 363-364.

17 World Health Organisation. Standard protocol for chemotherapy in a lepromatous leprosy. WHO Geneva, 1982. Document TOR/THELEP/PROTOCOL/82.1.

18 Haldar SR, Pahwa VK, Ramadasan P, Tutakne MA. Tuberculoid granuloma in a clinically normal looking skin. Ind J Lepr, 1988; 60: 277-279.

19 Talwar S, Jha PK. Correspondence on tuberculoid granuloma in a normal looking skin. Ind J Lepr, 1990; 62: 530.

${ }^{20}$ Rees RJW. New prospects for the study of leprosy in the laboratory. Bull WHO, 1969; 40: 785-800.

21 Srinivasan H, Rao KS, Lyar CGS. Discrepancy in the histopathological features of leprosy lesions in the skin and peripheral nerve. Lepr India, 1982; 54: 275-282. 


\title{
Lèpre névritique: épidémiologie et sensibilité à la thérapeutique
}

\author{
S TALWAR, P K JHA ET V D TIWARI
}

Résumé Nous avons étudié l'épidémiologie, l'évolution et la réponse au traitement dans 62 cas de lèpre névritique. L' hypoesthésie était le principal symptôme observé. L'observation la plus fréquente était celle d'une mononévrite intéressant le nerf cubital, puis le nerf sciatique poplité externe. Le test à la lépromine était positif dans 34 cas tandis que le frottis de peau fendue était toujours négatif. Nous avons traité 20 de ces cas par la dapsone seule; 5 d'entre eux $(25 \%)$ ont présenté des lésions cutanées après 3 mois de traitement en moyenne. Nous avons traité 42 cas par une association de dapsone et rifampicine; 3 d'entre eux ont présenté une lésion cutanée après 2 à 6 mois de traitement en moyenne. Les diagnostics suivants ont par la suite été éstablis dans les cas présentant des liaisons cutanées: lépromateux borderline-un cas; tuberculoide borderline- 4 cas; tuberculoide-2 cas; indéterminé-un cas.

\section{La lepra neuritica: las reacciones epidemiologicas y terapeuticas}

\section{S TALWAR, P K JHA Y V D TIWARI}

Resumen Hemos estudiado la epidemiología, progreso y respuesta terapéutica en 62 casos de lepra neurítica. El síntoma principal que se presentó fue adormecimiento. La presentación más común fue mononeuritis implicando el nervio ulnar, seguido por el nervio peroneal. La prueba de lepromina fue positiva en 34 casos y, al mismo tiempo, un "smear" de incisión de piel fue negativo en todos los casos. Tratamos 20 de estos casos por monoterapia con dapsona, y 5 casos $(25 \%)$ desarrollaron una lesión cutánea después de una duración media de tratamiento de 3 meses. Tratamos 42 casos con una combinación de dapsona y rifampicina, y 3 casos (7\%) desarrollaron una lesión cutánea después de una duración media de 2 a 6 meses. El diagnóstico posterior en los casos que desarrollaron lesiones cutáneas fue lepromatoso incierto en 1 caso, tuberculoide incierto en 4 casos, tuberculoide en 2 casos e incierta en 1 caso. 